\title{
The complexity of mathematics teaching and learning in mathematics teacher education and research
}

\author{
Despina Potari
}

Published online: 23 March 2012

(C) Springer Science+Business Media B.V. 2012

Coping with the complexity of mathematics teaching and learning in the practice of teaching is an everyday task for a mathematics teacher, teacher educator, and researcher. Krainer (2003) considers that the field of mathematics education has moved toward a better understanding of this complexity: "The growth of mathematics education as a scientific field can be regarded as a continuous process of having a deeper and deeper understanding of the complexity of learning and teaching” (p. 93). In mathematics teacher education research, as reported in a number of articles of the Journal of Mathematics Teacher Education (JMTE), this complexity is tackled in different ways and contexts. Some studies are exploratory with a focus on how teachers cope with the classroom complexity. Others are developmental in the sense of creating contexts for teachers, which would promote their awareness of the complexity of teaching and learning mathematics and support them to cope with this in the classroom.

At the exploratory level, the complexity lies in the classroom interactions and the ways that the teacher is balancing mathematical goals, students' reasoning and thinking, and classroom management. As Wood (2002) argues, the alternate forms of teaching and the research on them have brought under consideration situations such as classroom norms, patterns of interaction, supporting students' mathematical thinking, and reasoning as important issues in mathematics teaching that pose new challenges for the teacher, the teacher educator, and the researcher. Moving beyond this micro level of the mathematics classroom and addressing wider social factors that frame mathematics learning and teaching, Valero (2010) addresses another layer of complexity involving a network of different practices that seem to frame the didactical triangle and emphasizes the need for mathematics education research to consider the connections between these different practices and mathematics teaching and learning. Sullivan (2006), in his editorial, also offers specific examples to indicate that ambiguities that exist in curriculum goals and in research findings create dilemmas to teachers and teacher educators who try to balance different and often dichotomous goals of mathematics teaching. These complexities raised

D. Potari $(\bowtie)$

Department of Mathematics, University of Athens, Panepistimioupolis, 15784 Athens, Greece e-mail: dpotari@math.uoa.gr 
by these three authors provide a view of issues that require ongoing consideration on the exploratory level.

At the developmental level, there is an increasing number of studies that investigate how to link the complexity of mathematics teaching and learning to the education of prospective and practicing teachers. Wood and Berry (2003), for example, stress the importance of generating and sharing knowledge among teachers concerning the complexity in mathematics teaching. Design research, action research, lesson study, and professional communities are some of the approaches that have been developed to allow mostly practicing teachers to inquire mathematics teaching and learning. At the prospective teacher level, some of these approaches have more recently been adopted. However, their effect on teacher development is still questioned, while other ways such as the analysis of videos and classroom tasks are also being more systematically studied as a basis of supporting teachers' learning.

At the level of research on mathematics teacher education, a dominant area of study that addresses the complexity of mathematics teaching and learning involves mathematics teacher knowledge. In these studies, researchers often adopt different theoretical perspectives and develop different analytical tools, which have their own issues and complexities, as a means of establishing and investigating connections between practice and teacher knowledge. For example, while the work of Shulman (1986) has been influential to this area of study, his notion of pedagogical content knowledge as used by many researchers does not provide a complete view of this knowledge. More recent works (e.g., Ball et al. 2008) have been focusing on defining a perspective of this knowledge specific to mathematics education, that is, mathematics knowledge for teaching. But a number of researchers adopting a situated approach challenge the existence of an abstract construct that describes teacher knowledge (Hodgen 2011). These issues add another layer to the complexity of addressing the challenges of mathematics teaching and learning and mathematics teacher education and suggest the need for ongoing investigation of mathematics teacher knowledge and how it relates to practice.

The three research reports and the book review that are published in this issue of JMTE consider in different ways the complexity of mathematics teaching and learning both in the design of their studies and in the findings. At the same time, the implications of these studies on the practice of teacher education and subsequently on the practice of mathematics teaching and learning are also issues that are addressed.

Two of the articles refer to mathematics teacher knowledge. In the article "The Nature and Development of Middle School Mathematics Teachers' Knowledge”, Kim Berswick, Rosemary Callingham, and Jane Watson developed an instrument for measuring middle school mathematics teachers' knowledge. The authors initially discuss the various attempts that have been made to measure mathematics teacher knowledge in the context of teaching and report on the different dimensions that have been identified and tested. They support a comprehensive conception of teacher knowledge that extends the identified in the literature dimensions by including affective aspects such as beliefs and confidence. They also claim that this position could make it easier to study links between teacher proficiency to student achievement, an area that is important to consider both at research and practice level of mathematics education. Based on this conception, the authors pose a methodologicaltheoretical question about whether it is legitimate to consider these various types of teacher knowledge as a uni-dimensional construct instead of measuring them separately. To answer this question, they designed a measuring instrument, which was completed by 62 Australian middle school mathematics teachers. The statistical analysis of the data validated the hypothesis that teacher knowledge for mathematics teaching could be considered 
as an entity. It identified a 4-level structure of teacher knowledge. The levels indicate different degrees of teachers' confidence in their own capacities to use mathematics in everyday life, their confidence to teach mathematics, their beliefs about mathematics teaching and learning, their pedagogical content knowledge, and their general pedagogical knowledge. Higher levels of knowledge are related to beliefs about the value of struggle with mathematical ideas, the importance of using students' ideas, justifying mathematical claims, fostering inquiry, teaching mixed ability groups, and the need to have classroom tasks relevant to students. Issues that emerged concerned: the distinction between beliefs about mathematics and about teaching and learning; the limited role of confidence to use mathematics and teach mathematics on teacher knowledge that is required for effective mathematics teaching; and the parallel development of general pedagogical knowledge and pedagogical content knowledge.

A main contribution of this study is to develop an instrument for measuring teacher knowledge that addresses affective dimensions and appreciation of the complexity of teaching mathematics. The authors recognize that although the categorization of teacher knowledge has contributed to the development of our understanding about mathematics teaching and teacher development, it has some limitations in addressing the reality and complexity of mathematics teaching and learning. I think that the idea of the uni-dimensional teacher knowledge offers a new dimension to the research on mathematics teacher knowledge that can provide us with a less fragmented research approach. However, questions still remain about the possibility to use this theoretical and methodological approach to study mathematics teacher knowledge required for teaching at secondary or tertiary level or in different educational contexts. Another concern is in what ways under this theoretical position we could investigate the process of mathematics teacher development using qualitative approaches.

The second article that focuses on mathematics teacher knowledge is "Relationships between Mathematical Knowledge for Teaching and Teaching Practice: The Case of Proof" by Michael Steele and Kimberly Cervello Rogers. The study reports attempts to link two different paths to investigate mathematics knowledge for teaching proof, one is based on the use of clinical instruments such as assessment tasks or interviews, while the other on the analysis of classroom teaching. The main goal of this study is methodological in the sense that the authors aim to identify the possibilities and limitations that each approach has on the process of studying mathematical knowledge for teaching proof and its relation to teacher practice. A cycle that interrelates research and practice seems to appear in the paper. For example, the authors developed a framework on the basis of existing research on students' and teachers' knowledge of proof, which they used to design assessment tasks. They used teachers' responses to the tasks to identify their mathematical knowledge for teaching and to investigate its impact on their classroom teaching. The knowledge that emerged from the analysis of the classroom teaching in contrast with the one that emerged in the clinical setting offers new insights to research and theory on mathematics teacher knowledge.

A particular focus of the article is on two contrasting cases of secondary school mathematics teachers, a novice and an expert, who introduce proof writing for the first time to their students. In the clinical assessment setting, the teachers' responses on a written assessment and on a semi-structured interview were analyzed, while in the classroom setting, one videotaped lesson was the data used. The analysis indicates that although the mathematics knowledge for teaching of the two teachers shared similar characteristics, the actual teaching involved a number of different issues such as the task selection and implementation and the way each teacher positioned their student. The latter seemed to be 
crucial on the opportunities that the students were given to experience the different characteristics and roles of mathematical proof in mathematics and in mathematics teaching and learning.

A main contribution of this study is that it indicates the affordances of examining mathematics knowledge for teaching in multiple settings and how roles taken by teachers, students, or even the textbooks interact with this knowledge. In a different direction, both theoretical and methodological, from the article of Beswick, Callingham, and Watson, it also addresses the complexity of the construct of mathematics teacher knowledge by focusing especially on its relation to practice. It also suggests that content-specific knowledge can be the starting point for teacher education by providing mathematical lenses for prospective and practicing teachers to inquire into their own teaching.

The article "Learning to Pose Cognitively Demanding Tasks through Letter Writing" by Anderson Hassel Norton and Signe Kasiberg focuses on the growth of prospective teachers in terms of their ability to design cognitively demanding tasks in the context of letter-writing exchanges with high school students. Letter writing proves to be a context that allows prospective teachers to experience the complexity of mathematical learning and teaching. Through a process of designing tasks, evaluating their cognitive demands, comparing their expectations of students' responses to the actual ones, and restructuring their initial tasks, the two prospective teachers that are discussed in this study seem to appreciate at a certain degree students' mathematical thinking and transform their knowledge of tasks in the light of this experience. However, one prospective teacher seems to attribute the disparities between expected and actual mathematical activity almost exclusively on student's responsibility and in particular on the lack of effort, while the other seems to appreciate the characteristics of the task and the way that she managed the interaction, as basic factors of the disparities between the two.

The authors refer to the "unsuccessful" prospective teacher as an example for encouraging mathematics teacher educators to think about the disparities between their expectations of their own students' reactions and their actual responses. They suggest that similar to what teacher educators expect their prospective teachers to do with their students, they (teacher educators) need to avoid being critical about their own students and passing the responsibility of growth only to them even if they think that they have provided great opportunities for their professional development. The authors also suggest that teacher educators need to reconsider their practices, question the effectiveness of tools that they often use with their students (e.g., the use of "rubrics" for designing and evaluating tasks), encourage their prospective teachers to form interpretations of students' responses based on the existing research literature, and foster class discussions about the relationship between students' mathematical thinking and task design.

A main contribution of this study is the design of an intervention in a teacher education program that seems to allow prospective teachers to focus on students' mathematical thinking and on how this can be related to the design and transformation of a mathematical task. This study is a part of a wider project that exploits the letter-writing approach with prospective secondary school teachers, which some studies have found to be effective with prospective elementary school teachers. Comparing what these two different groups of prospective teachers "see" in the tasks they design and in students' reactions will possibly indicate the role of different mathematical and meta-mathematical understandings the groups carry in the process of their personal growth as teachers.

Margaret Walshaw's review of the book "Becoming a mathematics teacher: Identity and identifications" by Tony Brown and Olwen McNamara addresses an alternative way to the scholarship that we are familiar with regarding the process by which beginning teachers 
form a professional identity. The review addresses the complexity of the design and interpretation of data collected through the stories that teachers describe to researchers about their past, present, and future experiences as learners and teachers. The authors' position that the experience of teaching is never transparent precisely and therefore cannot be understood only through consciousness challenges existing research and policy that provide structure about how teachers conceive themselves as teachers. Furthermore, the process of forming a teaching identity is not individualistic in the sense of forming inner mental capacities, but is a complex phenomenon that is framed by the participation of the beginning teachers in different practices. Although this position makes the work of a mathematics teacher educator and researcher a bit "unstable" and "unsafe," it makes them more aware of the conflicts and tensions that the beginning teachers face in their first teaching experiences when they try to balance their university experience to the school policies that indicate a particular pedagogy, often conflicting from the one the university researchers expect them to develop.

Although the three research articles of this issue and the book review seem to address different themes in mathematics teacher education, such as, teacher knowledge, professional growth, and teacher identity, I think that they all offer to mathematics teacher education research theoretical, methodological, and practical ways of addressing the complexity of mathematics teaching and learning both in the research and practice of mathematics teacher education. Moreover, they provide opportunities for us to rethink our own research and practice as well as to question and challenge existing theoretical and methodological constructs that have been established in our field under a more contextual, social, and international perspective.

Being a new associate editor of JMTE, I would like to thank Olive Chapman for this invitation. I know that this will be a great learning opportunity for me collaborating with her, the other members of the Editorial team, and, of course, all the reviewers and authors who work very hard to sustain the high quality of JMTE.

\section{References}

Ball, D. L., Thames, M. H., \& Phelps, G. (2008). Content knowledge for teaching: What makes it special? Journal of Teacher Education, 59(5), 389-408.

Hodgen, J. (2011). Knowing and Identity: A situated theory of mathematics knowledge in teaching. In T. Rowland \& K. Ruthven (Eds.), Mathematical knowledge in teaching (pp. 27-42). Dordrecht: Springer.

Krainer, K. (2003). Teams, communities and networks. Journal of Mathematics Teacher Education, 6, 93-105.

Shulman, L. S. (1986). Those who understand: Knowledge growth in teaching. Educational Researcher, 15, 4-14.

Sullivan, P. (2006). Dichotomies, dilemmas and ambiguity: Coping with complexity. Journal of Mathematics Teacher Education, 9, 307-311.

Valero, P. (2010). Mathematics education as a network of social practices. In Proceedings of CERME 6 , January 28th-February 1st 2009. Lyon: France.

Wood, T. (2002). Demand for complexity and sophistication: Generating and sharing knowledge about teaching. Journal of Mathematics Teacher Education, 5, 201-203.

Wood, T., \& Berry, B. (2003). What does "design research" offer mathematics teacher education? Journal of Mathematics Teacher Education, 6, 195-199. 